\title{
Problematising current forms of legitimised participation in the examination papers for Mathematical Literacy
}

\begin{abstract}
Authors:
Marc North ${ }^{1,2}$

Iben M. Christiansen ${ }^{1}$

Affiliations:

${ }^{1}$ School of Science,

Mathematics and Technology

Education, University of

KwaZulu-Natal, South Africa

${ }^{2}$ Centre for Research in Mathematics Education, University of Nottingham, United Kingdom
\end{abstract}

\section{Correspondence to:}

Marc North

Email:

marc.north@nottingham.ac.uk

\section{Postal address:}

Room B44, Dearing Building,

Jubilee campus, University of Nottingham, NG8 1BB,

United Kingdom

\section{Dates:}

Received: 26 Nov. 2014

Accepted: 25 Apr. 2015

Published: 29 June 2015

How to cite this article: North, M., \& Christiansen, I.M. (2015). Problematising current forms of legitimised participation in the examination papers for Mathematical Literacy. Pythagoras, 36(1), Art. \#285, 11 pages. http://dx.doi. org/10.4102/pythagoras. v36i1.285

\section{Copyright:}

(C) 2015. The Authors. Licensee: AOSIS OpenJournals. This work is licensed under the Creative Commons Attribution License.
In this article we argue that in South Africa the current format of legitimised participation and practice in the examination papers for Mathematical Literacy restricts successful apprenticeship in the discipline of scientific mathematics and limits empowered preparation for real-world functioning. The currency of the subject, then, is brought into question. We further argue that the positioning of the subject as a compulsory alternative to Mathematics and the differential distribution of these two subjects to differing groups of learners facilitates the (re)production and sustainment of educational disadvantage. We draw on Dowling's theoretical constructs of differing domains of mathematical practice and positions and focus analysis on a collection of nationally set exemplar Grade 12 examination papers to identify legitimised forms of participation in the subject. We conclude by arguing for a reconceptualised structure of knowledge and participation in Mathematical Literacy and make preliminary recommendations in this regard.

\section{Introduction}

The secondary school subject Mathematical Literacy ${ }^{1}$ (ML) has faced increasing criticism in recent years, with some positing the subject as a second-rate qualification to Mathematics 'Mathematical Literacy (which is little more than arithmetic) is to Mathematics what spelling is to writing' (Oberholzer, 2012, slide 14) - and others calling for the removal of the subject from the secondary school curriculum framework (for e.g., see Jansen, 2012).

We contend that current criticism is grounded in three main concerns relating to the structure, status and practices of the subject. Firstly, the ML examinations are perceived to be considerably less demanding than those in Mathematics - and the high pass rate of $87.1 \%$ in the subject compared to $59.1 \%$ in Mathematics in the 2013 academic year provides some validation for this concern. This state of affairs is seen to contribute to the exodus of increasing numbers of learners from Mathematics to ML (enrolment in Mathematics has decreased significantly since the introduction of ML - from 60.1\% in 2006 to 42.7\% in 2013) (Department of Basic Education [DBE], 2014a, pp. 125, 159; Department of Education [DOE], 2008, p. 27). Secondly, there is an accompanying concern that participation in the subject does not afford access to the same and equally varied and comprehensive avenues of study or career choice as Mathematics. In this regard, ML is perceived as a limiting qualification; this is why increasing enrolment figures in the subject at the expense of enrolment in Mathematics is of such concern. It is in response to concerns such as these that the current Minister of Education instituted a ministerial panel to investigate, amongst other things, 'the currency of Mathematics and Mathematical Literacy and whether this is the best option for the South African schooling system in terms of preparing learners for the workplace and for higher education studies' (DBE, 2013, p. 4). The third concern draws directly from the two previous concerns and is the topic of particular and primary relevance in this article. This concern relates specifically to the mismatch between the stated curricular intention of the subject for preparing and empowering participants for more effective and empowered functioning in complex contextual sense-making practices encountered in everyday life, the workplace and in a democratic society (DBE, 2011, p. 8) - what Venkat (2010, p. 55) refers to as a life-preparedness orientation - and current legitimised forms of participation in the examinations for the subject that prioritise engagement with elementary mathematical structures in largely contrived reconstructions of real-world practices. This mismatch is explicitly recognised and highlighted in the findings and recommendations of the above mentioned ministerial panel who argue for heightened emphasis

\footnotetext{
1.In South Africa participation in the subject Mathematics (comprising scientific mathematics contents) is compulsory up to the end of Grade 9 . At the Literacy. Mathematics is characterised by the study of scientific, abstract or esoteric mathematical contents; Mathematical Literacy, on the other hand, is characterised by engagement with everyday problem-solving situations and the utility of mathematics in those situations. A detailed discussion of the intention and philosophy of the subject, together with analysis of the existing body of literature on the subject, is provided in (North, 2015, Chapter 8). A similar discussion and analysis of international conceptions of mathematical literacy, quantitative literacy and numeracy (and the distinctions between these) is found in Chapters 5-7 of that same work.
} 
on the curriculum policy intentions, particularly in relation to areas of teaching, assessment and examinations (DBE, $2014 \mathrm{~g}$, pp. 12, 54-58). A consequence of this mismatch is that participation in the subject ML is reserved primarily for 'weaker' learners who are perceived to be unable to cope with the demands of scientific mathematics contents. In the South African context, such learners are, predominantly, learners who are located in poorly resourced schools situated in lower socio-economic environments. Given the positioning of ML as a qualification that involves engagement with only limited forms of mathematical participation, these (increasing numbers of) 'weaker' learners who engage in the subject are denied access not only to an educational experience that would better prepare them for life and the world of work, but also to a vast array of study and career opportunities which would facilitate upward social and economic mobility. We contend that the existing structure of mathematically legitimised participation in the subject contributes to the (re) production and sustainment of a degree of educational and social disadvantage. Our intention in this article is to employ a theoretically informed analysis of practices in the subject as evidenced in the structure of participation legitimised in nationally set Grade 12 exemplar examinations for the subject - to validate this claim.

At a general level this article builds on the work of others such as Christiansen (2006), Julie (2006), Frith and Prince (2006) and Venkatakrishnan, Graven, Lampen and Nalube (2009), all of whom have problematised components of policy and practice associated with the subject Mathematical Literacy. Specifically, however, this work is an extension and elaboration of the work of Christiansen (2007), but with important differences. Firstly, Christiansen performed an analysis of the curriculum for the subject prior to the implementation of the curriculum at classroom level and, as such, was only able to make predictions regarding possible formats of classroom practice. This article, by contrast, has been written eight years after the initial implementation of the subject and after five cohorts of learners have passed through the subject structure. Furthermore, this article is focused on analysis of empirical practices contained in national examinations for the subject - which, in turn, are seen to directly influence and determine the structure of legitimised forms of participation with the contents of the subject at classroom level. In alternative terms, where Christiansen's analysis focused on the field of official recontextualisation, the analysis in this article is focused on the field of pedagogic recontextualisation (cf. Bernstein, 1996). Secondly, the original NCS curriculum that formed the primary focus of Christiansen's analysis has been replaced by a restructured curriculum contained in the Curriculum and Assessment Policy Statement (CAPS) (DBE, 2011). This CAPS curriculum is characterised by a modified statement of intention and philosophy for the subject and by a reformulated statement of intended focus for pedagogic and assessment practices. The analysis in this article, then, is more directly relevant to and reflective of current empirical practices and forms of legitimised participation in the subject.
The following structure applies in the article. In the next section we provide an overview of aspects of Dowling's (1998) theoretical language relating to domains of mathematical practice, positions and apprenticeship in mathematics. In the subsequent section we employ these theoretical constructs in analysis of an amended OR reworked 2014 exemplar national Grade 12 ML examinations. Here we argue that the examinations prioritise a form of participation in the subject characterised by engagement with, primarily, public and descriptive domain of mathematics type practices. As a consequence, learners are relegated to positions of dependency and objectification in pedagogic processes and are denied the opportunity for successful apprenticeship in the discipline of mathematics. We argue further that it is this characteristic of the structure of endorsed participation in the examinations that contributes to the devaluing of the qualification and facilitates a degree of educational disadvantage. In the final section of the article we suggest an alternative structure of endorsed participation for the subject characterised by the promotion of a life-preparedness orientation (Venkat, 2010) and argue tentatively that this alternative structure may prompt a more empowering educational experience for participants in the subject.

\section{The relevance of Dowling's theoretical language to the empirical terrain of Mathematical Literacy}

A key issue we seek to highlight in this article is that despite curriculum intentions for the prioritisation of contextual sense-making practices, participation in ML is endorsed and evaluated primarily according to mathematical structures and mathematically legitimised forms of practice. The work of Dowling (1998) provides a useful means for identifying and describing the characteristics of the dominant form of legitimised participation and practice in the subject - as elaborated below.

Importantly for the contents of this article - focused as it is on the empirical terrain of the subject ML - a key aspect of Dowling's work involves analysis of the relationship between mathematical and extra-mathematical knowledge, contents, discourse and practices. A central argument in this regard is that academic (generally) and mathematical (specifically) activities are incommensurate with everyday activities and that academic mathematical knowledge cannot be used as a theory for facilitating adequate or appropriate understanding of everyday practices. For Dowling, exclusive or predominant participation in particular forms of contextualised mathematics practices inhibits mathematical understanding and affords only a limited degree of lifepreparation (1995a, p. 9, 1995b, p. 209). Dowling argues further that the consequence of this is particularly experienced in the schooling system where mathematics focusing on relevance is commonly made available to learners who are deemed to have lower mathematical ability (many of whom are located in predominantly working-class 


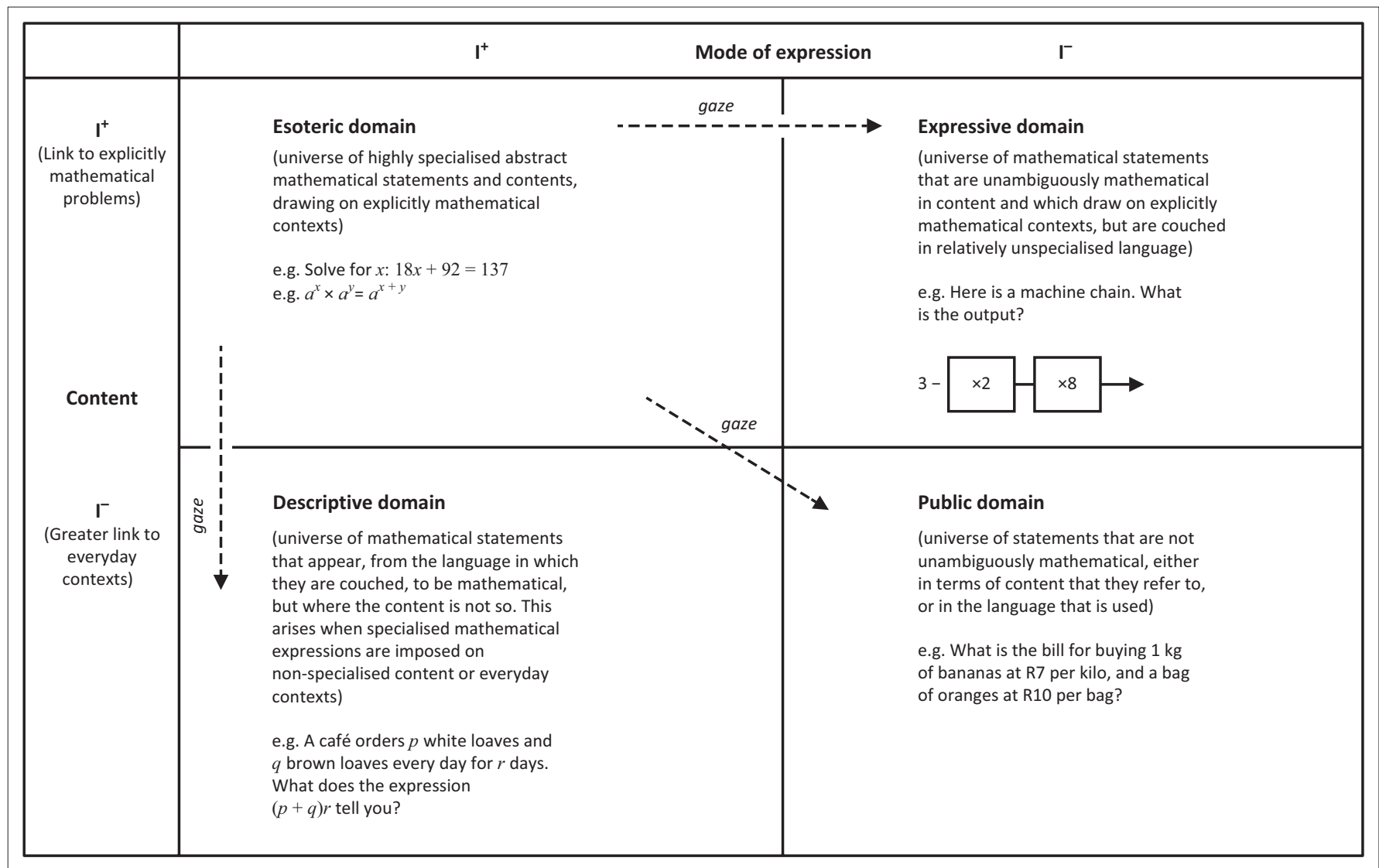

Source: Adapated from Ensor, P., \& Galant, J. (2005). Knowledge and pedagogy: Sociological research in mathematics education in South Africa. In R. Vithal, J. Adler, \& C. Keitel (Eds.), Researching mathematics education in South Africa: Perspectives, practices and possibilities (pp. 281-306). Cape Town: HSDRC Press; Dowling, P. (1998). The sociology of mathematics education: Mathematical myths/pedagogic texts. London: Routledge Falmer.

FIGURE 1: Domains of mathematical practice.

environments) whilst abstract mathematics is made available to supposedly higher ability learners (many of whom are located in better resourced schools situated in middle-class environments). The 'weaker' learners from poorer socioeconomic environments are, thus, exposed to a form of mathematics that is limiting, both in terms of mathematical and real-world understanding and also in terms of future study and career opportunity. It is in relation to this situation that emphasis on relevance in mathematics is deemed to facilitate the production and sustainment of a degree of educational difference and disadvantage (Dowling, 1994, p. 138, 1998, pp. 236-241, 2010a, slide 2; Hoadley, 2007, p. 684). Given the high degree of correlation between these identified areas of focus in Dowling's theoretical language and the structure of participation in the subject ML that is promoted in the examinations - namely, as a subject reserved for learners of supposedly weaker mathematical ability and, yet, characterised by the prioritisation of mathematical structures in encounters with heavily mathematised reconstructions of real-world problem-solving scenarios - it is appropriate to employ elements of this theory in analysis of empirical examination-related practices in the subject.

\section{Domains of practice, positions and apprenticeship in mathematics}

The discussion in this section of the article is specifically concerned with what Dowling (1998) refers to as the structural level of his theoretical language - namely, the dimension of the language that facilitates identification and description of the positions filled by participants in an activity and the practices that those participants engage in within the activity. ${ }^{2}$

\section{Domains of mathematical practice}

Dowling (1998) identifies four domains of mathematical practice (see Figure 1), each of which is characterised by differing strengths of institutionalisation (i.e. the degree of specialisation) of mathematical contents and mode of expression employed in the messages through which the practices of the activity are transmitted. Importantly for the discussion on the empirical terrain of the subject ML, contents refers not only to specific knowledge or skills (i.e. the topics of mathematics), but also to the nature of the context mathematical or extra-mathematical - from which the content is drawn (Sethole, Goba, Adler \& Vithal, 2006, p. 119). Mode of expression, on the other hand, refers to the means through which these contents are transmitted, together with the words, method and language used in the transmission of a message. Drawing on the above, strong institutionalisation (I+) of the mode of expression and content in a statement or problem is characterised by explicit reference to, engagement with and

2.Dowling also constitutes textual and a resources levels for his theoretical language. See Dowling (1998, pp. 131-132, 150-154) for elaborated discussions of these levels. 
use of specialised mathematical entities or explicitly intramathematical contexts. Weak institutionalisation (I-), by contrast, is characterised by restricted reference to specialised entities (Dowling, 2008a, p. 15) and/or by engagement with extra-mathematical contexts and contents (Sethole et al., 2006, p. 119).

The esoteric domain of mathematical practice is characterised by a high degree of institutionalised practice (I+) and comprises explicitly specialised, generalisable and abstracted mathematical contents, contexts, principles, symbols and statements: 'the esoteric domain comprises the specialised forms of expression and content which are unambiguously mathematics' (Dowling, 1994, p. 130). For Dowling (2008b, p. 4), this is the domain that contains the non-negotiable part of school mathematics and what is considered to be legitimate mathematical practice. Given the high degree of specialisation of both content and mode of expression, the mathematical principles that regulate the practices of the activity and the principles against which the practices of the activity are evaluated are explicit in this domain (Dowling, 1994, p. 129) and learners who engage with mathematical knowledge and practices in this domain have full access to these principles. Furthermore, Dowling (1998) argues that it is only in this domain that full access to these principles is possible:

Because ambiguity is minimised in the esoteric domain, specialised denotations and connotations are always prioritised. It is, therefore, only within this domain that the principles which regulate the practices of the activity can attain their full attention. The esoteric domain may be regarded as the regulating domain of an activity in relation to its practices. (p. 135)

However, school mathematics contains more than just this highly specialised non-negotiable domain of practice. Rather, pedagogic practice facilitates the casting of a gaze beyond the esoteric domain to establish links between this domain and the extra-mathematical world: 'The practice [mathematics] must also constitute a more weakly institutionalised region in order to permit entry into it; this is the public domain' (Dowling, 2010a, slide 2). The result of this mathematical gaze, as extra-mathematical settings are appropriated in the mathematics classroom and colonised according to mathematical principles and structures, is the development of the public domain of school mathematics as a collection of recontextualised and reformulated or mathematised problems (Dowling, 2008b, p. 4). Problems posed in this domain are weakly institutionalised in terms of both content and mode of expression, with the consequence that the practices of this domain appear to be and are experienced as being about something other than mathematics: 'mathematics parading as something other than itself' (Dowling, 2001, p. 20). Crucially, the public domain is not to be equated with reality or with the real-world. Rather, it is the space where the everyday represents a recontextualised, virtual and distinctly mathematised and, hence, mythologised representation of reality.
The expressive domain of practice is also constituted through the imposition of a mathematical gaze from the esoteric domain on the terrain of the extra-mathematical and represents an alternative form of recontextualisation than in the public domain. In this domain, nonmathematical modes of expression (I-) are appropriated for use within explicitly intra-mathematical contexts and are employed to give expression to specialised mathematical contents (I+) (Dowling, 1998, pp. 135-136). Elsewhere, Dowling (2010a, slide 2) refers to this domain as the domain of pedagogic metaphors, where fractions are equated to pieces of cake and where words such as sharing are employed to facilitate understanding of abstract concepts such as division.

As with the public and expressive domains of practice, the descriptive domain is a further form of esoteric domain gaze recontextualisation. In this domain, specialised mathematical modes of expression (I+) are employed to model nonspecialised contents and/or extra-mathematical contexts (I-) (Dowling, 1998, p. 136). This is the domain that reflects modelling practices - where mathematics is employed in the generation of descriptions of extra-mathematical contents and contexts.

Importantly, the generative, regulative and evaluative esoteric domain principles that define the recontextualisation process and, consequently, the structure of legitimate participation in these domains, cannot be fully realised in practices that remain exclusively in these domains and which do not make a deliberate move into the esoteric domain and towards a degree of abstraction and generalisation:

the esoteric domain must signify differently because of the recruitment of a non-mathematical setting, so that, once again, the principles of the esoteric domain cannot be made fully explicit within [these] domain[s]. (Dowling, 1998, p. 137)

Furthermore, the identified domains of practice are not mutually exclusive in the sense that engagement with public domain contents precludes engagement with esoteric domain contents. Rather, and as is discussed in more detail below, for Dowling the development of mathematical knowledge and, particularly, successful apprenticeship in the discipline of mathematics, are facilitated through traversal of the entire terrain.

\section{Positions}

The activity of Mathematics also constitutes positions in relation to how knowledge and available practices are distributed to participants in the activity (Dowling, 1998, p. 131). Dowling identifies four possible positions - Subject, Apprentice, Dependent and Object. The Subject of an activity has mastered the practices and regulating principles of the activity. This position is the most dominant position and every other position is to a greater or lesser extent subordinated to or objectified by the Subject (Dowling, 1998, p. 140). 
By contrast, participants in the Apprenticeship position engage in the practices of the activity with the intention, at some point in the future, of becoming potential Subjects of the activity:

Successful apprenticeship to an activity is achieved (metaphorically) upon the completion of a one-hundred-andeighty-degree rotation of the apprentice who thereby 'moves' from 'outside' to 'inside' the activity and becomes its Subject. (Dowling, 1998, p. 123)

The Dependent position is a subordinated position to the Apprentice in respect to the Subject. This position is occupied by participants who are unable to access (or are denied access to) the regulating principles of an activity, commonly through the interference of extra-mathematical elements that obscure these principles. In such instances, participants are dependent on the Subject to make visible and explicit the regulating principles according to which any mathematisation processes of non-mathematical elements have been conducted. This position is particularly characteristic of practices that remain primarily within the expressive or descriptive domains of mathematical practice, where the inclusion of non-mathematical expression and contents can serve to inhibit access to the regulating esoteric mathematical principles that structure a problem. Participants in the Dependent position are not construed as potential future Subjects (as with the Apprentice position). Consequently, the final career outcome of such participants is less certain: the Apprentice will become the Subject, but the only certainty for the Dependent is their reliance on the Subject to mediate the practices of the activity (Dowling, 1998, p. 141).

Importantly, participants in the Dependent position may be fully aware that they are operating outside of the public domain and that encountered problems are mathematical in nature, but are thereby reliant on a Subject of the activity to make visible and accessible the underlying generative and regulating esoteric domain knowledge, principles and practices. Not so with the Objectified position. This position occurs primarily in relation to public domain practices characterised by the recontextualisation of real-world practices according to the principles of the esoteric domain via an imposed mathematical gaze by either the Subject or another party on an extra-mathematical context. When practices are recontextualised in this way, participants are invited to recognise themselves in the problems, as though the problems are their own and relate to and have relevance to their lives: learners are invited to become objects in the problems (Dowling, 1996, p. 402) - for example, as a shopper who needs to solve a problem involving a cost comparison. This is in contrast to the Apprentice position where the individuality and identity of the participant remain exterior and irrelevant to the context and problem (Dowling, 1996, p. 402). Participants who are objectified in a practice believe (or are led to believe) that they are operating inside of the domain of the practice (for example, as shoppers in a supermarket) rather than in the domain of mathematics. For this reason they are construed as neither Subjects nor Dependents of mathematical practices since they believe that they are engaged in non-mathematical activities. The consequence is that such participants operate with no or only restricted independent and/or unaided awareness of and access to the esoteric domain principles that regulate the practice. Furthermore, since the recontextualised practice represents a mythologised version of the real-world practice, and because the mathematics is hidden in the practice, within this position the learners learn sufficiently neither about mathematics nor about real-world practices (Dowling, 1998, p. 141).

\section{Apprenticeship in mathematics}

In establishing an explicit connection between the differing domains of practice and positions in these domains, consideration must be given to the conditions under which successful apprenticeship in mathematics is to be achieved. Ensor and Galant (2005, p. 297) argue that apprenticeship in mathematics is achieved 'when learners ... have grasped the "generative principles" (Dowling, 1998) of whatever discourse they have been inducted into, and are able to produce appropriate learning performances'. Since it is only in the esoteric domain of mathematical practice that learners are exposed to the generative, regulative and evaluative principles that define and structure legitimate knowledge and participation in the discipline of mathematics, successful apprenticeship in school mathematics is only possible if participants engage in and with esoteric domain practices (Dowling, 1998, p. 140).

The reverse is true of practices that remain in the public domain and, to a lesser extent, the expressive and descriptive domains. Participants exposed exclusively to public domain practices do not gain direct access to the esoteric mathematical principles underpinning the practices since these are obscured and overshadowed by the interference of weakly institutionalised contents and modes of expression. Such participants are more likely to be positioned as Dependents or Objects: the mythologising of the public domain practices as valid representations of reality and the objectification of participants in the problem-solving process render the participants dependent on the Subject of the activity to make explicit the underlying (mathematical) regulating principles and the criteria according to which mathematisation processes have been conducted (by either the Subject or by another party) in the generation of public domain contents (Dowling, 1998, p. 141). A similar situation applies for practices embedded exclusively or primarily within the expressive and descriptive domains (and which do not make an explicit reach to esoteric domain contents), where the inclusion of non-mathematical elements serves to inhibit access to and understanding of the mathematically regulated principles of encountered problems. However, in these domains participants are fully aware that the problems are regulated according to mathematical principles and so are not objectified through the problem-solving process. Nonetheless, participants remain dependent on a Subject to make more explicit and to facilitate access to the mathematical 
principles and structures that regulate participation in the practice.

However, this does not mean that the teaching of mathematics should confine itself only to the esoteric domain. Rather, potential subjects for an activity are attracted to an activity through the public domain: 'The public domain is, in this sense, the principal arena in which an activity selects its apprentices' (Dowling, 1998, p. 149). As such, if no projection is made from the esoteric domain to the public domain, then no new apprentices will be 'hailed' into the activity (Dowling, 1998, p. 141). Importantly, the move from the public domain to the esoteric domain is not a direct process. Rather, the expressive domain of practice provides a bridge for the transition between these domains by facilitating engagement with more explicit mathematical contents through reference to familiar non-mathematical expressions. Equally, the descriptive domain provides a bridge from the esoteric to the public domain: once esoteric domain contents have been mastered, a mathematical gaze is able to be cast over the practices of world to facilitate the description of these practices according to mathematical structures. As summarised by Dowling (2008a):

There is no natural route into the esoteric domain of mathematics ... Nor, of course, can mathematics education begin and remain exclusively in the esoteric domain; there has to be a way in and this will always be via the public domain. Pedagogic action must then construct trajectories that lead into the esoteric domain via the expressive and that lead to the public domain from the esoteric via the descriptive. ... in general, in respect of any specialist region of mathematics, the whole of the map should be traversed in one way or another. (p. 27)

As such and in summary, apprenticeship of students into mathematics, in Dowling's terms, involves the successful move from public to esoteric domain. Interruption of this trajectory inhibits students' ability to master mathematics. (Ensor \& Galant, 2005, p. 297)

\section{Domains of practice and positions embodied within the Grade 12 Mathematical Literacy exemplar examinations $^{3}$}

\section{Why a focus on examinations?}

According to Dowling (1998, p. 120), 'Activities are produced by and reproduced in human subjects - who move, routinely, between activities - and by texts'. Focus on the

\footnotetext{
3.The decision to focus analysis on a set of exemplar examinations and not on the final end-of-year nationally set examinations is deliberate and is driven by logistical constraints with respect to the availability of examinations based on the recently implemented CAPS curriculum process. At the time of writing, the first official fina Grade 12 national examinations for the CAPS curriculum have not yet been written and the recently distributed exemplar Grade 12 examinations that are the focus of the analysis process in this article are the only currently available examination of the analysis process in this article are the only currently available examination papers that directly reflect the structure and form of the forthcoming final Grade 12 CAPS-related examinations. It is our belief that since these exemplar examination serve as an example of and precursor to the final examinations and are set by the same national examining panel, the structure of endorsed participation legitimise in or through engagement with these examinations can be taken to be reflective of the structure of legitimate participation to be prioritised in the final examination papers.
}

national examination papers thus provides a particular site of identification and analysis of the dominant practices and positions legitimised and prioritised for the subject ML. The examinations provide a useful site of analysis for two further reasons. Firstly, the examinations reflect current official state opinion on the structure of legitimised and endorsed participation with the contents of the subject. Secondly, the structure of endorsed participation espoused in the national examinations has a 'backwash effect' (Allais, 2007) on pedagogic practice by informing the dominant orientation and forms of participation legitimised by teachers as they prepare learners for the examinations. That said, the limitations of the conducted analysis are acknowledged, particularly with respect to any conclusions made regarding pedagogic practice within classroom settings.

\section{Background information on the structure of the examinations}

Examinations in ML are characterised by two examination papers that are differentiated according to cognitive demand. Paper 1, classified as a basic skills paper, is focused on the assessment of proficiency of basic skills and knowledge of both mathematical and contextual contents; it comprises questions posed primarily at the two lowest levels of the four-level assessment taxonomy. Paper 2, by contrast, characterised as an applications paper, is focused on assessment of the ability to engage with both mathematical and non-mathematical techniques and considerations in contextual problem-solving processes. This paper comprises questions posed primarily at the two highest levels of the assessment taxonomy (DBE, 2014f, pp. 5, 7).

Crucially, the CAPS curriculum document prioritises as a primary goal in the subject, engagement with authentic contexts and resources that bear a high degree of resemblance to real-world practices (as opposed to contrived, mathematised or fictitious contexts) and a focus on the development of an enhanced understanding of these contexts (as opposed to a dominant emphasis on the development of mathematical knowledge) (DBE, 2011, pp. 8-11). There is, thus, every expectation that this impetus is reflected in the exemplar examinations.

\section{Demonstration of the method used for categorising questions}

Consider the question extract shown in Figure 2. Importantly, the Department of Basic Education did not respond to our request for permission to use an extract from the exemplar examination papers. As such, Figure 2 shows a re-modelled version of Question 1.2 in the exemplar Paper 1 examination (DBE, 2014b, p. 4). Although the contextual scenario and question phrasing are different in this remodelled version (the exemplar examination makes reference to the context of landline telephone tariffs), we have made every effort to ensure that the core concepts and domain of practice prioritised in each question bear close resemblance to the original examination question. That said, we acknowledge 
1.2 Jemima is investigating two different electricity tariff systems. The tariffs for each system are shown in table below:

\section{TABLE 1: Electricity Tariffs}

\begin{tabular}{|l|c|c|}
\hline & Cheep-Cheep & Bright-Sparks \\
\hline Fixed monthly fee & R255,00 & --- \\
\hline Free units & 120 units & 60 units \\
\hline $\begin{array}{l}\text { Consumption charge } \\
\text { (per unit of electricity } \\
\text { used after the free } \\
\text { units are finished) }\end{array}$ & R0,70 & R0,95 \\
\hline
\end{tabular}

1.2.1 If Jemima were to opt for the Cheep-Cheep system, calculate how much would it cost her to use an additional 850 units of electricity once all of the free units have been used? Give your answer in rand.

1.2.2 The table below shows the variable costs for electricity usage on each system.

TABLE 2: Variable costs for electricity usage on each system

\begin{tabular}{|l|c|c|c|c|c|c|c|}
\hline $\begin{array}{l}\text { Units of electricity } \\
\text { usage }\end{array}$ & 0 & 60 & 120 & 150 & 200 & 240 & $\mathrm{R}$ \\
\hline $\begin{array}{l}\text { Cost on the Cheep- } \\
\text { Cheep system }\end{array}$ & 0 & 0 & 0 & 246 & 281 & $\mathrm{Q}$ & 365 \\
\hline $\begin{array}{l}\text { Cost on the Bright- } \\
\text { Sparks system }\end{array}$ & 0 & 0 & 57 & $\mathrm{P}$ & 133 & 171 & 247 \\
\hline
\end{tabular}

(a) Calculate the missing values $\mathbf{P}, \mathbf{Q}$ and $\mathbf{R}$

(b) The graph showing the variable costs for the BrightSparks system has been drawn on ANNEXURE A Draw, on the same ANNEXURE, the graph showing the variable costs for the Cheep-Cheep system.

FIGURE 2: Remodelled version of a Paper 1 examination question.

the potential challenge to the validity of the analysis process of the exemplar examinations based on the method employed and demonstrated through analysis of a reformulated task.

The first thing to notice is that the questions are pre-empted by and based on a contextual scenario; this is a common strategy and occurrence in the examinations as well as in pedagogic practices in the subject. Although our analysis is focused primarily on the type of practice prioritised in engagement with these scenarios, it is worth noting that many of the contextual scenarios employed draw on deliberately constructed fictitious situations and resources. For example, although the scenario of electricity costs is realistic in South Africa, there are no such systems as Cheep-Cheep and Bright-Sparks (and no such telephone system as the Scamtho 250 cited in the examination paper) and the tariff structures associated with electricity or telephone contracts are seldom as simple (or as simply presented) as portrayed here. In the context of the examinations, employed contextual scenarios are largely deliberately constructed to facilitate evaluation of particular mathematical and calculation-based processes.

With respect to the questions developed for engagement with this contextual scenario, Question 1.2.1 is characterised by the usage of, primarily, non-specialised references to everyday forms of expression, with no explicit signification given on the structure of the institutionalised mathematical content required for answering the question (and it is only through the inclusion of the vocabulary signifier calculate that an indication is given of a requirement for a form
TABLE 1: Categorisation of the exemplar examination questions according to Dowling's (1998) domains of practice schematic.

\begin{tabular}{lcccc}
\hline Variables & Public & Expressive & Descriptive & Esoteric \\
\hline Paper 1 & & & & \\
Count & 32 & 0 & 26 & 0 \\
$\%$ count & 55.2 & 0.0 & 44.8 & 0.0 \\
Mark totals & 72 & 0 & 78 & 0 \\
$\%$ marks & 48.0 & 0.0 & 52.0 & 0.0 \\
Paper 2 & & & & \\
Count & 22 & 0 & 18 & 0 \\
\% count & 55.0 & 0.0 & 45.0 & 0.0 \\
Mark totals & 82 & 0 & 68 & 0 \\
$\%$ marks & 54.7 & 0.0 & 45.3 & 0.0 \\
Combined & & & & \\
Count & 54 & 0 & 44 & 0 \\
$\%$ count & 55.1 & 0.0 & 44.9 & 0.0 \\
Mark totals & 154 & 0 & 146 & 0 \\
$\%$ marks & 51.3 & 0.0 & 48.7 & 0.0 \\
\hline
\end{tabular}

of mathematical engagement with the scenario). In this question, then, participants are led to believe that this is an actual real-world scenario and that they are engaging with the scenario in a way that reflects real-world practice. As a result, this question is categorised as reflecting a form of mythologised practice associated with the public domain. Question 1.2.2 (a), by contrast, makes reference to a resource involving largely non-specialised contents (namely, electricity costs), but employs a specialised mode of expression through reference to missing variables that have been imposed on the unspecialised context. As such, this question and the resource required for the successful completion of the question are categorised as reflecting a form of practice associated with the descriptive domain. A similar classification applies to Question 1.2.2 (b), where a specialised mathematical mode of expression (i.e. a graph) is referenced for use in relation to an extra-mathematical context and unspecialised contents.

\section{Categorisation of the examination paper questions according to the domains of mathematical practice}

The information in Table 1 shows the count and percentage of the questions in the examination papers categorised according to the identified domains of mathematical practice.

\section{Discussion}

The complete absence of both esoteric and expressive domain contents in the examinations is immediately noticeable from the information shown in Table 1: participants in this subject are clearly not being apprenticed in the discipline of scientific mathematics. This finding is unsurprising given that the subject is directed at learners who are unable to cope with the demands of the scientific Mathematics course and is focused, instead, on engagement with elementary mathematical principles in contextualised problem-solving scenarios. However, herein lies a contradiction: even though apprenticeship in esoteric domain mathematics practices is entirely absent, the fact that all of the examination questions are able to be categorised in the domains of mathematical 
practice schema signifies that legitimate participation and practice in the examinations are regulated by mathematical structures and principles. Learners who supposedly are unable to engage with esoteric mathematical contents continue to be regulated and evaluated according to mathematically defined and imposed knowledge, structures and principles. This observation gives rise to a further question of what, precisely, participants in the subject are being apprenticed into - clearly not mathematics, so what then? Perhaps, as suggested by the curriculum statement for the subject, the answer lies in more empowered and effective participation in real-world practices: 'The subject Mathematical Literacy should enable the learner to become a self-managing person, a contributing worker and a participating citizen in a developing democracy' (DBE, 2011, p. 8). However, the spread of all of the questions within the domains of mathematical practice schema undermines and negates this intention. By way of explanation, consider that there are 21 instances in the combined examinations that reflect contextual scenarios (and associated resources) comprising characteristics of constructed or fictitious situations, deliberately developed to facilitate evaluation of engagement with particular mathematical processes. Only four instances (Paper 1: 3.1 and 5.1.5; Paper 2: 2.1 and 2.1.3) reflect an expectation for engagement with real-world practices through exposure to unaltered and authentic contextual resources. ${ }^{4}$ This is significant in that the examinations posit engagement with mathematised, virtual and mythologised representations of reality as the dominant terrain of contextual engagement in the subject, which again reinforces the dominance of esoteric mathematical principles as the basis of legitimate participation and negates the potential for engagement in the subject to serve as a means for empowered functioning in real-world practices. Whether or not Dowling's framework is employed as a lens for analysis, it remains obvious that virtually every question in the examinations is driven almost exclusively by mathematical goals - either the assessment of a specific mathematical technique or the recollection of a form of mathematical knowledge. In this sense, the majority of the supposedly real-world contexts employed are superfluous mere window dressing, since the dominant orientation involves the assessment of mathematical techniques and knowledge and not authentic and enhanced contextual sense-making practices. Enhanced understanding of contextual environments and contextually legitimate forms of participation is thus negated in the examinations. As predicted by Christiansen (2007, p. 91), participants in the subject ML, then, are seemingly stranded in 'no-mans-land between mathematics and life-related content', both denied apprenticeship in mathematics and restricted in preparation for real-world functioning.

4.Question 3.1 references a table of seemingly authentic statistical data (togethe with a source reference for the data); Question 5.15 references a tax bracket with a source reference for the data), Question 5.1 .5 references a tax bracket table; Question 2.1 includes information and a photograph of the SALT telescope in Sutherland; Question 2.1.3 shows a cross-sectional representation of the telescope (which an Internet search revealed is an authentic resource source from the website for the South African Astronomical Observatory (see http://www. saao.ac.za; interestingly, this source reference for the diagram is not given in the examination paper!).
This situation is exacerbated by the fact that the esoteric mathematical generative and evaluative principles that regulate the criteria for successful and legitimate participation in the subject are rendered hidden and inaccessible to the participants through a dominant focus on questions in the examinations that require engagement with public and descriptive domain practices. In other words, despite the complete exclusion of esoteric domain practices, the authors of the examination papers deliberately prioritise engagement with forms of practice that reflect varying degrees of esoteric domain recontextualisation. In this regard, the number of questions associated with public domain practices dominate throughout both examination papers (although more marks are allocated to descriptive domain practices in the Paper 1 examination) and instances of objectification are commonplace: ' 1.4 Write down another reason, excluding the profit, why the committee decided to use venue ABC.'; '3.1.4 (c) Justify Megan's claim that the price of a 9-year-old pre-owned Smart car could be worth R50 000.' (DBE, 2014c, pp. 4, 7). This emphasis on public domain practices signifies the prioritisation on the part of the examiners of the 'myth of participation' (Dowling, 1998) as a key component of the structure of legitimate pedagogic action in the subject. The prioritisation of descriptive domain practices is also significant, reflecting a heightened expectation for participants to employ distinctly mathematical modes of expression in engagement with unspecialised contents in a variety of contextual settings, albeit with awareness of the mathematically legitimated basis of any generated descriptions. It is particularly significant that this emphasis on descriptive domain practices occurs in conjunction with the complete exclusion of esoteric domain contents: although learners are expected to employ specialised, mathematically legitimated forms of expression in solving problems, at no point are they afforded formal and explicit access and exposure to the esoteric mathematical principles that regulate and structure these expected forms of expression. This emphasis on descriptive domain practices is somewhat in contradiction to the equally dominant emphasis on public domain practices (at the complete expense of esoteric and expressive domain practices): by emphasising public domain practices, the authors are encouraging participants to identify with problem scenarios, to draw on their own experiences in solving those problems and to envision how they might engage with the problems if encountered in their own daily life settings; however, by then placing almost equal emphasis on descriptive domain problems the examiners are also encouraging the dominance of mathematical modes of expression and mathematically orientated descriptions in problem-solving processes. This could lead to confusion on the part of some learners about the domain of practice and associated criteria according to which the structure of legitimate participation in different questions in the examinations will be evaluated by the examiners. ${ }^{5}$ 5.See (Cooper \& Dunne, 2000) for a detailed discussion of the ways in which learners
of varying mathematical competence and different social class backgrounds might respond differently to assessment tasks that include realistic elements. 
The prioritisation of public and descriptive domain practices to the complete exclusion of esoteric domain practices ensures that learners in the subject are positioned as dependents in the learning process, commonly objectified by the problemsolving scenarios, but seldom (if ever) given direct and explicit access to the specialised esoteric principles that define and regulate the structure of legitimate participation in these scenarios. Learners in the subject are continuously required to engage mathematical principles in contextual problem-solving situations, but seldom (if ever) exposed to processes involving generalisation and abstraction of these principles. Learners in the subject are consistently required to engage in mathematised problem-solving scenarios, but seldom (if ever) empowered to engage in the mathematisation processes. Instead, learners are reliant on their teachers to uncover and make explicit the mathematically structured principles (decided on by others) according to which legitimate and endorsed participation in the problem-solving processes are defined and evaluated. Time and time again, learners are exposed to mathematised forms of contextual situations that bear only limited resemblance to reality and, yet, are presented as opportunities for empowered real-world functioning. All of the above indexes not only a limited and limiting form of participation in the discipline of mathematics, but also stunted preparation for enhanced real-world functionality.

However, as noted in the introduction, the pass rate in ML is significantly higher than that in Mathematics. This begs the question that if ML is not affording access to mathematics nor to life preparation, then what is the high pass rate indicative of? We contend that it is the distinction between the two examination papers and, specifically, the presence of the basic skills paper (which only assesses questions posed at the two lowest levels of the taxonomy of cognitive demand) that is contributing to the significantly high pass rate in the subject. In this regard, the high pass rate is indicative only of the ability of the learners to engage in simplistic and low-level numeracy-type calculations hence the criticism that ML is an easier qualification than Mathematics and offers less opportunity for career recruitment.

As a final observation, it is worth mentioning that the dominance of public and descriptive domain practices in the examinations highlights a degree of inconsistency with the intention of the CAPS curriculum and with the statement of intention and philosophy for the subject espoused in that curriculum. The CAPS curriculum, both through stated intention (see DBE, 2011, pp. 8-14) and also through curriculum and assessment structure (see DBE, 2011, pp. 12-14, 96-97, 104-109), prioritises a dominant intention for contextual sense-making practices over the development of mathematical knowledge: mathematics is posited as one of several elements required for effective engagement in sense-making practices of authentic real-world contexts. This intention suggests engagement with contextual environments, practices, considerations and forms of participation that do not fit within Dowling's domains of mathematical practice schema - namely, with practices in which the generative principle of the structure of legitimate participation does not rest exclusively in the domain of esoteric mathematics. This curricular intention is clearly not achieved in the examination papers.

\section{$M L$ in the secondary schooling framework: the promotion of educational disadvantage?}

Since it is the contents and the traits of practices associated with the esoteric domain contents that are privileged for 'recruiting to careers' (Dowling, 1996, p. 393), Mathematics in South Africa is posited as a gateway subject to participation in numerous fields of tertiary study and future career choice. ML, by contrast - due to the limited degree of mathematical apprenticeship and restricted empowerment for real-world functioning afforded through participation in the subject - is perceived as a limiting qualification with a significantly lower study and employment currency than Mathematics. Now consider that within the secondary schooling curriculum framework, participation in the subject ML is reserved primarily for learners of supposedly weaker mathematical ability, many of whom are located in poorly resourced schools situated in poorer socio-economic environments. These learners are encouraged to participate in a qualification that provides not only a limited learning experience in the classroom, but also limited opportunity for future study and career choice and, hence, for social and economic advancement. Further, given that the number of learners enrolled in the subject exceeds those in Mathematics and is still increasing, it is of little wonder that there is heightened concern from certain quarters of the mathematics education community regarding the suitability and viability of the subject as a compulsory alternative to a scientific mathematics course. Thus, despite curricular intentions for 'social transformation', 'social justice' and 'inclusivity' (DBE, 2011, pp. 4-5), the inclusion of ML in the South African schooling system, and particularly the orientation of the subject towards public and descriptive domain mathematical practices, facilitates rather than alleviates an element of educational disadvantage.

\section{Conclusion: Towards an alternative vision for Mathematical Literacy}

Given the identified problematic structure of existing mathematically legitimised forms of participation in the subject, we suggest that an alternative conception of the structure of legitimate knowledge and participation is necessary. Although it is still in development, we posit tentatively at this stage that this revised knowledge structure is dominated by a life-preparedness orientation (Venkat, 2010) which, in turn, we characterise as comprising a dominant agenda for contextual sense-making practices and a dominant intention for the critical evaluation of both mathematical and contextual structures encountered in the real-world problem-solving process. In this revised conception, any and all mathematics appropriated in the midst of contextual 
sense-making practices is done so in service to the goal of the development of an enhanced and broader understanding of appropriate and legitimate forms of participation in those contexts. Mathematics is, thus, replaced by the ability to identify, engage with and model contextually appropriate and endorsable forms of participation in real-world practices as the structuring principle of legitimate participation in the knowledge domain. It is our contention that this revised structure of legitimate participation has the potential to negate the mythologising associated with current mathematicallylegitimised forms of participation in the subject and to offer a more empowered form of participation and more effective preparation for enhanced real-world functioning in the world beyond the walls of the classroom. Further details of our preliminary thinking on the components of this envisioned knowledge structure can be found in North (2015).

\section{Post script}

At the time of final edits to this article the official end-ofyear 2014 Grade 12 Mathematical Literacy examinations (DBE, 2014d, 2014e) have been written. Public and descriptive domain practices continue to dominate in these examinations (to the exclusion of esoteric and expressive domain practices), albeit with a higher count of questions (55.1\%) and higher mark allocation (59.4\%) focused on public domain practices. We interpret this change as indicative of an attempt by the examiners to place heightened emphasis on problem-solving encounters that appear to bear closer resemblance to contextual practices (through a reduction in the degree of institutionalisation of expression and content in the problems). Of particular interest is the inclusion of a question (Question 4.4) that we contend is not able to be classified according to domains of practice schema due to the contextually prevalent form of practice and participation required and legitimised in the question. This signifies potential, albeit minor, consideration of an orientation towards life-preparedness.

\section{Acknowledgements}

This article was written whilst M.N. was a fellow in the Sasol Inzalo fellowship programme and would not have been possible without the generous support, financial and other, of the Sasol Inzalo Foundation.

\section{Competing interests}

The authors declare that we have no financial or personal relationships that might have inappropriately influenced us in writing this article.

\section{Authors' contributions}

M.N. (University of Nottingham) authored the article based on research conducted for his doctoral dissertation and was responsible for all alterations made during the review process. I.M.C. (University of KwaZulu-Natal) was the doctoral supervisor and provided substantial feedback on the component of the doctoral dissertation on which this article is based and also on the contents of this article.

\section{References}

Allais, M.S. (2007). Making educational judgements: Reflections on judging standards of intended and examined curricula. Pretoria: UMALUSI.

Bernstein, B. (1996). Pedagogy, symbolic control and identity: Theory, research and critique. London, UK: Taylor and Francis.

Christiansen, I.M. (2006). Mathematical Literacy as a school subject: Failing the progressive vision? Pythagoras, 64, 6-13. http://dx.doi.org/10.4102/pythagoras. v0i64.94

Christiansen, I.M. (2007). Mathematical Literacy as a school subject: Mathematical gaze or livelihood gaze? African Journal of Research in Mathematics, Science and Technology Education, 11(1), 91-105. Retrieved from http://hdl.handle. net/10520/EJC92659

Cooper, B., \& Dunne, M. (2000). Assessing children's mathematical knowledge: Socia class, sex and problem-solving. Buckingham: Open University Press.

Department of Basic Education (DBE). (2011). Curriculum and assessment policy statement: Mathematical Literacy. Pretoria: Author. Available from http:// www.education.gov.za/LinkClick.aspx?fileticket $=q 8+S k G y 43 \mathrm{rw}=\&$ tabid $=570 \& \mathrm{~m}$ id $=1558$

DBE. (2013). Government Gazette (Vol. 577, Issue 36677). Pretoria: Government Printers.

DBE. (2014a). 2013 National Senior Certificate Examination: National Diagnostic Report. Pretoria: Author. Available from http://www.education.gov.za/LinkClick. aspx?fileticket $=\operatorname{tn} \mid \mathrm{B}+\mathrm{PqQXu} 4=\& \mathrm{tabid}=358 \& \mathrm{mid}=1325$

DBE. (2014b). Grade 12 Mathematical Literacy exemplar paper 1 examination. Pretoria: Author. Available from http://www.education.gov.za/LinkClick.aspx?file ticket=ntL2Em9wY $\mathrm{Y}=\&$ tabid $=599 \&$ mid $=1802$

DBE. (2014c). Grade 12 Mathematical Literacy exemplar Paper 2 examination. Pretoria: Author. Available from http://www.education.gov.za/LinkClick.aspx?file ticket=JtztNKBSnaA=\&tabid=599\&mid=1802

DBE. (2014d). Grade 12 Mathematical Literacy paper 1 examination. Pretoria: Author. Available from http://www.education.gov.za/LinkClick.aspx?fileticket=BFEdSe3g $\mathrm{mpo}=\&$ tabid $=568 \& \mathrm{mid}=1528$

DBE. (2014e). Grade 12 Mathematical Literacy paper 2 examination. Pretoria: Author. Available from http://www.education.gov.za/LinkClick.aspx?fileticket=dpYnRvwtL $\mathrm{Ps}=\&$ tabid $=568 \&$ mid $=1528$

DBE. (2014f). Mathematical Literacy examination guidelines Grade 12. Pretoria: Author. Available from http://www.education.gpg.gov.za/Learners/Documents/ Mathematical Literacy GR 12 Exam Guidelines 2014 Eng.pdf

DBE. (2014g). The ministerial task team report on the National Senior Certificate (NSC). Pretoria: Author. Available from http://www.education.gov.za/LinkClick.as px?fileticket=VIFw9JGiNNo=\&tabid=358\&mid=1301

Department of Education. (2008). Education statistics in South Africa 2006. Pretoria: DOE. Available from http://www.dhet.gov.za/DHET Statistics Publication/DoE Stats at a Glance 2006.pdf

Dowling, P. (1994). Discursive saturation and school mathematics texts: A strand from a language of description. In P. Ernest (Ed.), Mathematics, education and philosophy: An international perspective (pp. 124-142). London: The Falmer Press.

Dowling, P. (1995a, January). Against utility in school mathematics and in education research: A voice from the twilight zone. Paper presented at the Annua Conference of the Southern African Association for Research in Mathematics and Science Education, Cape Town.

Dowling, P. (1995b). Discipline and mathematise: The myth of relevance in education. Perspectives in Education, 16(2), 209-226.

Dowling, P. (1996). A sociological analysis of school mathematics texts. Educationa Studies in Mathematics, 31(4), 389-415. http://dx.doi.org/10.1007/BF00369156

Dowling, P. (1998). The sociology of mathematics education: Mathematical myths/ pedagogic texts. London: Routledge Falmer.

Dowling, P. (2001). Mathematics education in late modernity: Beyond myths and fragmentation. In B. Atweh, H. Forgasz, \& B. Nebres (Eds.), Sociocultural research on mathematics education: An international perspective (pp. 19-36). New Jersey, $\mathrm{NJ}$ : Lawrence Erlbaum Associates.

Dowling, P. (2008a, May). What is Mathematics? The problem of recontextualisation. Paper presented at the University of Thessaly. Available from http://www. pauldowling.me/publications/dowling2008b.pdf

Dowling, P. (2008b, November). Mathematics, myth and method: The problem of alliteration. Paper presented at the Kings College, London. Available from http:// www.pauldowling.me/publications/dowling2008a.pdf

Dowling, P. (2010a, October). The problem of recontextualisation. PowerPoint presentation to the Japan Alumni Association. Available from http://www. pauldowling.me/presentations/Dowling2010.ppt

Ensor, P., \& Galant, J. (2005). Knowledge and pedagogy: Sociological research in mathematics education in South Africa. In R. Vithal, J. Adler, \& C. Keitel (Eds.) Researching mathematics education in South Africa: Perspectives, practices and possibilities (pp. 281-306). Cape Town: HSDRC Press. 
Frith, V., \& Prince, R. (2006). Reflections on the role of a research task for teacher education in data handling in a Mathematical Literacy education course. Pythagoras, 64, 52-61. http://dx.doi.org/10.4102/pythagoras.v0i64.99

Hoadley, U. (2007). The reproduction of social class inequalities through mathematics pedagogies in South African primary schools. Journal of Curriculum Studies, 39(6) 679-706. http://dx.doi.org/10.1080/00220270701261169

Jansen, J. (2012, 08 November). We can do the maths. Times Live. Available from http:// www.timeslive.co.za/opinion/columnists/2012/11/08/we-can-do-the-maths

Julie, C. (2006). Mathematical Literacy: Myths, further inclusions and exclusions. Pythagoras, 64, 62-69. http://dx.doi.org/10.4102/pythagoras.v0i64.100

North, M. (2015). The basis of legitimisation of Mathematical Literacy in South Africa. Unpublished doctoral dissertation. University of KwaZulu-Natal, Pietermaritzburg, South Africa.
Oberholzer, A. (2012, May). The dilemma of Mathematics and Mathematical Literacy. Paper presented at the Umalusi Maintaining Standards Conference, Johannesburg.

Sethole, G., Goba, B., Adler, J., \& Vithal, R. (2006). Fine-tuning a language of description for mathematics items which incorporate the everyday. In D. Clarke, C. Keitel, \& Y. Shimizu (Eds.), Mathematics classrooms in twelve countries: The insider's perspective (pp. 118-130). Rotterdam: Sense Publishers.

Venkat, H. (2010). Exploring the nature and coherence of mathematical work in South African Mathematical Literacy classrooms. Research in Mathematics Education, 12(1), 53-68. http://dx.doi.org/10.1080/14794800903569865

Venkatakrishnan, H., Graven, M., Lampen, E., \& Nalube, P. (2009). Critiquing the Mathematical Literacy assessment taxonomy: Where is the reasoning and the problem solving? Pythagoras, 70, 43-56. 